Article

\title{
Evaluation of Lightning Forecasting Based on One Lightning Parameterization Scheme and Two Diagnostic Methods
}

\author{
Ying Wang ${ }^{1,2}$ (D), Yi Yang ${ }^{2, *(1)}$ and Shuanglong Jin ${ }^{3}$ \\ 1 School of Marine Science, Nanjing University of Information Science and Technology, Nanjing 210044, China; \\ wangying_thw@nuist.edu.cn \\ 2 Key Laboratory of Arid Climatic Changing and Reducing Disaster of Gansu Province, College of \\ Atmospheric Sciences, Lanzhou University, Lanzhou 730000, China \\ 3 State Key Laboratory of Operation and Control of Renewable Energy \& Storage Systems, China Electric \\ Power Research Institute, Beijing 100192, China; ceprijins1@163.com \\ * Correspondence: yangyi@lzu.edu.cn
}

Received: 24 November 2017; Accepted: 7 March 2018; Published: 10 March 2018

\begin{abstract}
Lightning forecasting is a vital item in server convective system short-time forecasting. However, lightning parameterization in mesoscale numerical prediction models is still in its early stages of development. Several lightning parameterization schemes are implemented in the Weather Research and Forecasting (WRF) model. Data assimilation can provide a more accurate initial field, which could be useful for subsequent lightning forecasting. To evaluate its effect on lightning forecasting, a severe convective case that influenced Jiangsu and Anhui Province on 5 June 2009 is utilized and a series of experiments are conducted including assimilating radar reflectivity and lightning location network data via the three-dimensional variational (3DVar) method. Results show that data assimilation can effectively improve reflectivity forecasting and subsequent lightning forecasting. Lightning forecasting based on the PR92 lightning parameterization scheme, which is based on the convective cloud top height, offers a weaker magnitude forecast. The diagnostic method based on reflectivity and temperature has some spatial displacement. The potential forecast provided by lightning threat indexes produced an improvement in Anhui Province, while in other regions, it is located further east than the observation.
\end{abstract}

Keywords: lightning parameterization; data assimilation; lightning rate forecast

\section{Introduction}

During severe convective processes, lightning network observation systems can provide effective data which reflect the development of convective systems. However, lightning can lead to a large amount of disasters, which highlights the demand for accurate lightning forecasting during severe convection. In numerical weather prediction (NWP) models, the realization of lightning forecasts depends on the proper frame of the lightning parameterization scheme. Thus, it is vital to clarify the electrification mechanism in thunderstorm clouds first. The preliminary research into lightning depended on camera observation [1,2] to clarify the optical characteristics of lightning. Later on, some researchers used laboratory experiments to understand the electrification mechanism of lightning. Reynolds et al. [3] first proposed that the non-inductive process is the dominant electrification mechanism in convective clouds. They designed laboratory experiments to simulate the movement of graupel pellets in thunderstorm clouds. They found that the charges were exchanged owing to collisions between graupel and ice particles. Latham and Mason [4] found that the sign of the charging which results from collisions between ice crystals and a simulated hailstones is governed by that of 
the temperature difference, and it is rather insensitive to the size and impact velocity of the crystals. The controllable factor of charge transfer was found by Baker et al. [5]. Significant charging was obtained only when the interacting surfaces were growing due to vapor diffusion. The sign of the current, flowing to the simulated soft hailstone target in these circumstances was a sensitive function of time, liquid water content and temperature, while the temperature threshold of the sign of the current between liquid water and soft hailstone is about $-13^{\circ} \mathrm{C}[6]$.

Based on the research into lightning electricity and microphysical processes in thunderstorms over the past several decades, the development of lightning parameterization schemes has made it possible to offer direct lightning forecasting in NWP models. Nevertheless, when the initial field in the NWP model is not available to capture the main convective information, an accurate lightning forecast may not be achieved through lightning parameterization schemes. Lightning data assimilation could remedy this shortage when assimilating impactful lightning information into NWP models to provide a more accurate initial field. In the past decades, based on the microphysical mechanisms and dynamic variables in convective clouds, many researchers have tried to find a reliable relationship between lightning data and other meteorological variables to obtain a proper observation operator for lightning data assimilation. These variables are convective precipitation rate [7-10], convective available potential energy (CAPE) [11,12], maximum vertical velocity [13], proxy radar reflectivity [14-17], graupel mass [18], ice mass flux product [19,20], and updraft volume [21,22]. Then, researchers started to assimilate lightning data into NWP models. Alexander et al. [23] first demonstrated the benefit of satellite lightning data assimilation. They combined lightning flash observations together with a classic image processing technique to achieve a continuous time series for the rain rate, which is challenging over data-sparse regions. Results show that the lightning data has a greater positive impact on the forecasts than that from precipitation retrievals from passive microwave sensors and infrared sensors. Chang et al. [24] also confirmed that using lightning as a continuous precipitation proxy can improve weather forecasts. Stefănescu et al. [11] treated convective available potential energy as a proxy for lightning data. They selected the $1 \mathrm{D}+n \mathrm{D}$-VAR (one dimensional $+n$ dimensional variational) $(n=3,4)$ method to assimilate the Earth Networks Total Lightning Network (ENTLN) lightning data and evaluated its performance in two severe storm cases. Results showed that the best improvement was with the 1D + 4D-Var technique, which decreased the precipitation root mean square errors in both cases. Mansell et al. [25] utilized lightning as an index to control the Kain-Fritsch (KF) parameterization scheme for the presence or absence of deep convection, which showed successful improvement in generating cold pools at forecast initialization. Fierro et al. [26] suggested a simple relationship for a 9-km resolution simulation using assimilated lightning to enhance water vapor with the goal of improving the timing and location of convection. Qie et al. [27] utilized an empirical formula from Fierro et al. [26] and substituted the water vapor mixing ratio in the formula with the ice-phase mixing ratio to connect the total lightning flash rate with ice-phase particles. They then added the nudging function into the WSM6 (the WRF Single-Moment 6-Class) microphysical scheme of the WRF (the Weather Research and Forecasting model, Version 3.7.1) to adjust the mixing ratio of ice-phase particles between the $0{ }^{\circ} \mathrm{C}$ and $-20{ }^{\circ} \mathrm{C}$ isotherms. Results showed that the short-term precipitation forecast was improved. Benjamin [14] proposed a relationship between lightning data and radar reflectivity, which could convert lightning location network data into proxy radar reflectivity. This method is now being achieved on the Rapid Refresh (RR) platform to assimilate coastal lightning data. It can properly improve the convective forecast [14-17].

As lightning network data is not a conventional observed variable that can be directly assimilated into WRF, it has to be converted into other variables. In our previous work, we assimilated the cloud-to-ground or total flash rate into WRF via various methods. The cloud-to-ground flash rates were converted into proxy radar reflectivity basing on an empirical relationship in GSI (Girdpoint Statistics Interpolation) code, and then assimilated into the WRF model by physical initialization [28], WRF-GSI cloud analysis [29] and ensemble square root filter [30]. Total flash rates were converted into the proxy of relative humidity based on the relationship promoted by Fierro et al. [26] and 
then assimilated via three-dimensional variational (3DVar) [31]. These methods properly improved the form, development and movement of convective systems and revised the forecast of maximum reflectivity and precipitation. In this study, the 3DVar method is utilized to assimilate proxy reflectivity converted from cloud-to-ground flash, accompanied with lightning parameterization schemes, to offer an evaluation of the subsequent lightning forecast. At the same time, a radar data assimilation experiment was also conducted as a contrastive experiment. Moreover, the diagnosis basing on reflectivity and temperature and three kinds of lightning threat scores [32] in the National Severe Storms Laboratory (NSSL) are utilized to provide an equitable evaluation of the subsequent lightning forecast.

The remainder of this paper is organized as follows. Section 2 describes the main lightning parameterization scheme in WRF, Section 3 presents the experimental design, Section 4 provides an analysis of the results, and Section 5 presents a summary of the results.

\section{PR92 Lightning Parameterization Scheme in WRF}

WRF, as one of the mesoscale numerical prediction models, has started to offer intra-cloud and cloud-to-ground lightning forecasting based on some certain lightning parameterization schemes since version 3.5.1. The main lightning parameterization scheme is PR92, which is based on the research work of Price and Rind [13] and Wong et al. [33]. The WRF model can provide intra-cloud and cloud-to-ground lightning forecasts based on the parameterized partitioning method between intra-cloud and cloud-to-ground flashes. In 1989, Williams [34] proposed an empirical relationship between convective cloud top height and lightning frequency. The empirical relationship was obtained from northern-hemisphere, continental, mid-latitude thunderstorms. To verify the global applicability of this relationship, Price and Rind [13] utilized the International Satellite Cloud Climatology Project (ISCCP) C1 dataset to transfer the observed convective cloud top height into the flash rate and then compare the calculated values with available satellite observed lightning data. They found that the relationship proposed by Williams was only appropriate for observed lightning from thunderstorms that happened on land. When the underlying surface shifts to marine, greater convective cloud top height is obtained. However, the updrafts in marine thunderstorms are very weak, which leads to small charge buildup in clouds [13,35]. Thus, Price and Rind [13] proposed a simple lightning parameterization for different underlying surface categories. The PR92 lightning parameterization schemes are divided into two types. One takes less regard of underlying surface types to determine lightning frequencies via vertical updraft velocities. The other one to determine lightning frequencies via convective cloud top height for two kinds of underlying surface categories, land and marine. The details of the PR92 lightning parameterization schemes are introduced below [13,33].

The relationship between lightning frequency and maximum vertical velocity in the PR92 lightning parameterization scheme based on vertical updraft velocity is listed as follows.

$$
F=5.7 \times 10^{-6} w_{\max } 4.5
$$

Here, $w_{\max }$ is the maximum vertical velocity (unit: $\mathrm{m} \cdot \mathrm{s}^{-1}$ ) where the reflectivity is greater than $20 \mathrm{dBZ}$. $F$ is lightning frequency (unit: $\mathrm{min}^{-1}$ ).

The other kind of PR92 lightning parameterization scheme provides different formula according to the type of underlying surface category.

For land underlying surface:

$$
F_{c}=3.44 \times 10^{-5} H^{4.9}
$$

For marine underlying surface:

$$
F_{m}=6.4 \times 10^{-4} H^{1.73}
$$

$H$ is convective cloud top height (unit: $\mathrm{km}$ ), which is determined by the thresholds of reflectivity and temperature. The threshold of reflectivity is $20 \mathrm{dBZ}$ and that of temperature is $0{ }^{\circ} \mathrm{C}$. $F_{c}$ is the lightning 
frequency of the land underlying surface and $F_{m}$ is the lightning frequency of the marine underlying surface (unit: $\min ^{-1}$ ).

\section{Experiment Design}

In the WRF lightning parameterization scheme, whether lightning data assimilation could improve the subsequent lightning forecast still needs to be examined. To evaluate its effect on the lightning forecast, a convective case which influenced Jiangsu and Anhui Province on 5 June 2009 was chosen for this case study. The cloud-to-ground lightning data from Anhui Province was converted to proxy reflectivity. The relationship is based on the empirical profiles provided in the GSI code. First, cloud-to-ground data is interpreted into the grid point with a fixed resolution of $13.545 \mathrm{~km}$. Then, the two-dimensional flash rate is changed into maximum reflectivity according to an empirical table. The maximum reflectivity would be adjusted by different profile factors with different seasons to obtain three-dimensional proxy reflectivity. The proxy reflectivity is considered as an observation which would be assimilated into a WRF model. The details can be found in [28] or the code in GSI (The code file is gsdcloud/convert_lghtn2ref.f90 and the subroutine convert_lghtn2ref was used). The proxy reflectivity was then assimilated via 3DVar, and the following lightning forecast was conducted in WRF (Version 3.7.1). All the experiments were designed as below.

The first experiment was Exp. CTL, the baseline control experiment. It utilized the 0900 UTC (Universal Time Coordinated) forecast field which starts at 1800 UTC 4 June 2009, using the National Centers of Environmental Prediction (NCEP) Final Operational Global Analysis (FNL) data as the initial field, then forecast afterwards without any assimilation. The second experiment was Exp. radar, a radar assimilation experiment. It was based on the first experiment, Exp. CTL. It assimilated the observed radar reflectivity of the Hefei Doppler radar at 0900 UTC and then forecast afterwards. The third experiment was Exp. lightn, a lightning data assimilation experiment. It assimilated lightning-proxy radar reflectivity from the Anhui lightning location network at 0900 UTC based on Exp. CTL and forecast. The observed radar reflectivity or proxy radar reflectivity, which is converted from lightning location data was assimilated via 3DVar. Radar reflectivity can be directly assimilated into the WRF-3DVar system. It assimilates reflectivity via an operator to convert the model rainwater mixing ratio into reflectivity. A meaningful forecast rainwater field is difficult to obtain with a statistic background error covariance, which is utilized in the 3DVar framework [36,37]. Then, in its assimilating procedure, the total mixing ratio $q_{t}$ is utilized as the moist control variable. Then, warm rain microphysical processes are used to partition the total mixing ratio $q_{t}$ increment into the water vapor mixing ratio $q_{v}$, cloud water mixing ratio $q_{c}$ and rainwater mixing ratio $q_{r}$ increments (the details can be found in $[36,37]$ and the technical note on WRF-3DVar). The details of the designed experiments can also be obtained in Figure 1.

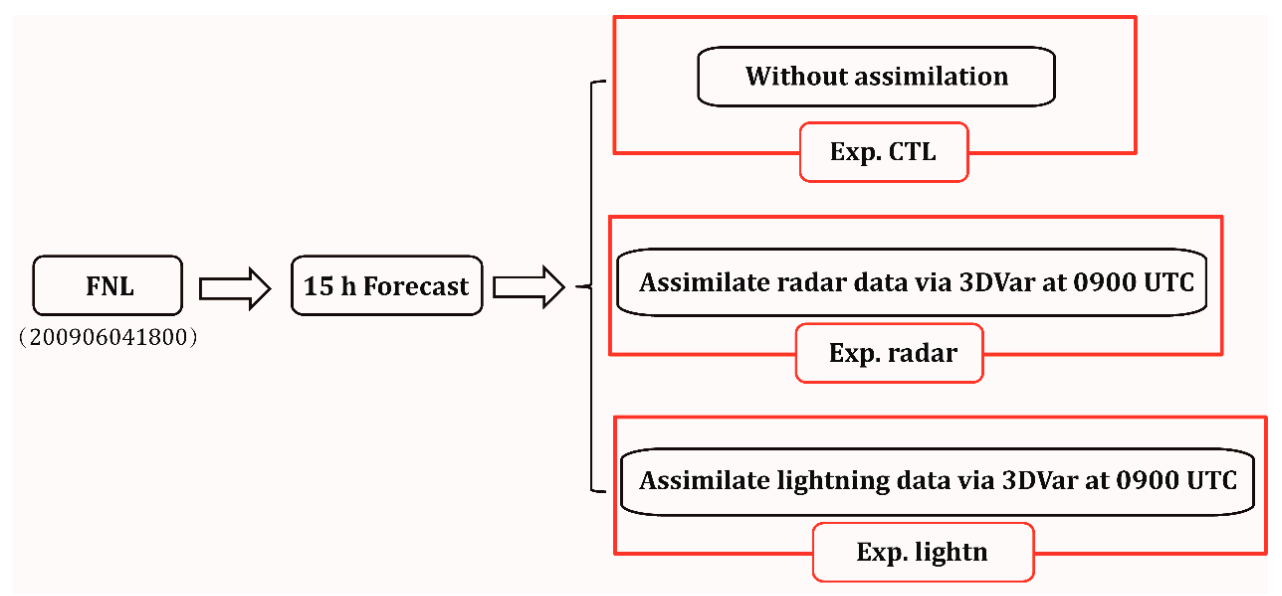

Figure 1. Flow chart of designed experiments. 
The Doppler radar data utilized in Exp. radar are from the Hefei Doppler radar, which is located at Hefei $\left(117.716^{\circ} \mathrm{E}, 31.833^{\circ} \mathrm{N}\right)$. It is a $10 \mathrm{~cm}$ wavelength Doppler radar with a $1^{\circ}$ half-power beam width. Reflectivity values are recorded at $1 \mathrm{~km}$ intervals along the radar beam and velocity parameters are recorded at $250 \mathrm{~m}$ intervals. The time of scanning each volume is approximate five minutes. The lightning data utilized in Exp. lightn are from the Anhui lightning location network. This network is primarily utilized to detect cloud-to-ground flashes. It can also differentiate the polarity of flashes. This network consists of 11 lightning location systems at Fuyang, Chuzhou, Luan, Anqing, Huangshan, Xuancheng, Bengbu, Huaibei, Tongling, Bozhou and Hefei. It is an LD-II lightning detector, manufactured by Huayun Company in Beijing. The detection distance is more than $600 \mathrm{~km}$ and the detection efficiency ranges from $90 \%$ to $95 \%$ within the available detection radius.

The resolution of the simulated domain, which is centered at Hefei, is $4 \mathrm{~km}$ horizontally. The simulated domain is shown in Figure 2. Vertically, there are 50 eta levels and the top pressure is $10 \mathrm{hPa}$. The time step is $20 \mathrm{~s}$. The main physical parameterization schemes are the Lin scheme [38], the Rapid and Accurate Radiative Transfer Model (RRTM) longwave scheme [39], the Goddard shortwave scheme [40], the Monin-Obukhov (Janjić) scheme [41,42], the Mellor-Yamada-Janjić (MYJ) Turbulent Kinetic Energy (TKE) scheme [41] and the PR92 lightning parameterization scheme [13], which is based on the convective cloud top height. Considering that the $4 \mathrm{~km}$ horizontal resolution is the upper limit of the cloud-resolving mode, convective parameterization is not being used.

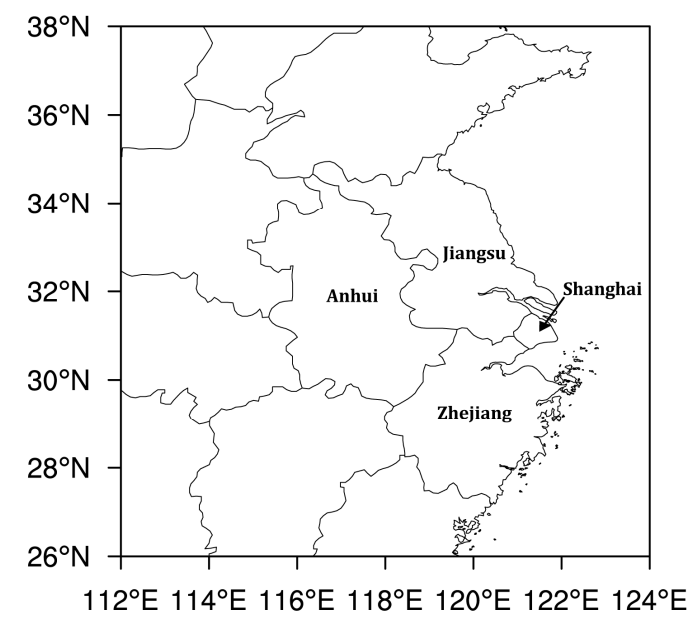

Figure 2. Horizontal extent of the simulated domain.

\section{Discussion of Results}

Figure 3 illustrates the observed maximum reflectivity and the forecast maximum reflectivity of all experiments. Columns (a)-(d) are the observed maximum reflectivity and the forecasts of Exp. CTL, Exp. Radar and Exp. lightn, respectively. Compared with the simulation with a resolution of $13.545 \mathrm{~km}$ in [28], the simulation with a resolution of $4 \mathrm{~km}$ in Exp. CTL captures more high reflectivity centers. However, compared with the observed radar reflectivity, the areas of high reflectivity north of Jiangsu and Anhui Province in Exp. CTL are still missing. After assimilating radar reflectivity, the forecast of the maximum reflectivity in Exp. radar at 1000 UTC improves a lot. The pattern of maximum reflectivity in Shanghai and north of Jiangsu Province is similar to the observed pattern, although there exists an overestimation in strength, while in Exp. lightn, the forecast maximum reflectivity is closer to the observed reflectivity. Compared with Exp. radar, the reflectivity in the central part of Anhui Province is better adjusted and the overestimation is lower than that of Exp. radar. In the time interval of 1400-1500 UTC, the main convective cell is located south of Anhui Province and west of Zhejiang Province. While the high reflectivity of the Exp. radar located in Shanghai and south of Jiangsu Province, which locates to the east of the observation. The forecast maximum reflectivity in 
Exp. lightn is located east of Anhui Province and north of Zhejiang Province, which provides a better location forecast than Exp. radar. From 1000 to 1500 UTC, the forecast maximum reflectivity of Exp. CTL and Exp. lightn are overestimated. However, as the integration time increases, the overestimation is not so obvious as the forecast is approaching to the observation. The improvement of forecast maximum reflectivity in these two assimilation experiments is well maintained and can last for more than $6 \mathrm{~h}$. In all, the first three hours forecast after assimilating the lightning data in Exp. lightn are overestimated, while the overestimation is lower than that of Exp. radar. In the following several hours, the pattern of maximum reflectivity maintains well and part of the high reflectivity is similar to the observed reflectivity.
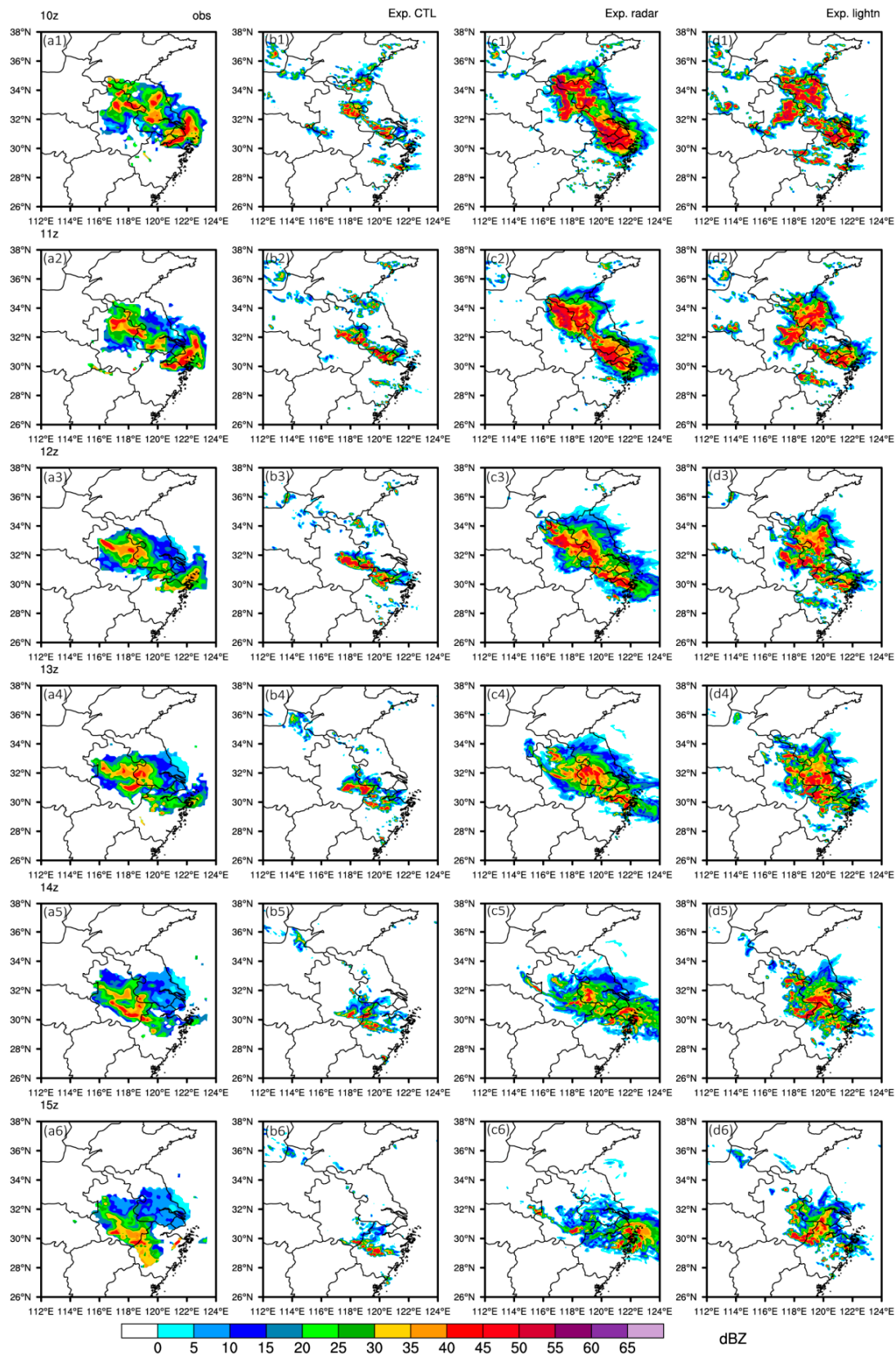

Figure 3. The observed maximum reflectivity (a) and forecast maximum reflectivity of (b) Exp. CTL, (c) Exp. radar and (d) Exp. lightn from 1000 to 1500 UTC (unit: dBZ). Line 1 to 6 represents different time point from 1000 to 1500 UTC. 
Here, some improvements in maximum reflectivity forecast have been achieved in the assimilation experiments. The evaluation of lightning rate forecast are also provided. Figure 4 shows the observed cloud-to-ground lightning rate and the forecast cloud-to-ground lightning rate of Exp. CTL, Exp. radar and Exp. lightn, hourly from 0900-1400 UTC. In this study, the default flash rate factor of 1.0 was utilized. From 0900 to 1400 UTC, the observed high lightning rate belt moves from north Anhui Province to south Anhui Province and north Zhejiang Province, and the hourly maximum accumulated lightning rate is higher than 6. In Exp. CTL, the position of the flashes matches well with the observations. However, the area is smaller than the observed area and only part of a lightning rate higher than 1 is forecast and the cloud-to-ground lightning rate is lower than 1 in most regions. In Exp. radar, as the maximum reflectivity is overestimated in the first several hours, as shown in Figure 3, and the location forecast of cloud-to-ground lightning is similar to that of the high maximum reflectivity. In the last two hours, all lightning rates in Exp. radar are very low, lower than 1, and the maximum is 1. The forecast lightning rate in Exp. lightn is similar to that in Exp. radar, with the value lower than 1 in most areas. Overall, based on the results of the forecast lightning rate, the PR92 lightning parameterization scheme that is based on the convective cloud top height can provide a proper forecast pattern of the accumulated cloud-to-ground lightning rate with a high resolution. However, the forecast lightning rate is pretty low, lower than 1 in most regions, thus it cannot provide an accurate, available, strong, cloud-to-ground lightning belt forecast. 

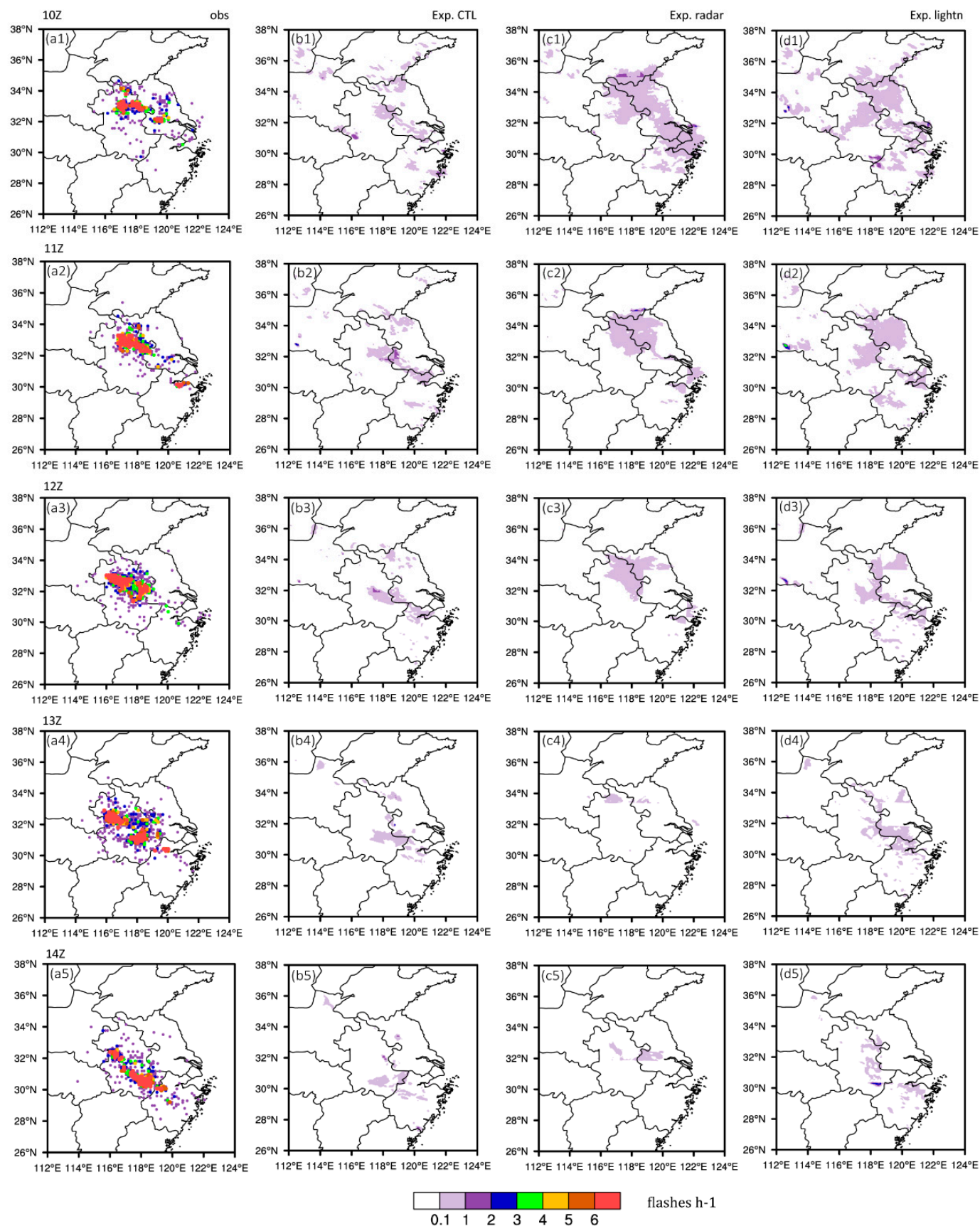

Figure 4. The observed cloud-to-ground lightning rate (unit: flashes $\cdot \mathrm{h}^{-1}$ ) (a) and forecast accumulated cloud-to-ground lightning rate (unit: flashes $\cdot \mathrm{h}^{-1}$ ) of (b) Exp. CTL, (c) Exp. radar and (d) Exp. lightn hourly from 0900 to 1400 UTC. Row 1 to 5 represents different time point from 0900 to 1400 UTC.

\section{Some Diagnosed Methods of Lightning and Analysis}

In this case study, the PR92 lightning parameterization scheme cannot provide an accurate lightning forecast. Thus, several diagnosed methods, which are diagnosed algorithms that offer a potential forecast of flashes, are utilized to make lightning location alarms based on the maximum reflectivity forecast shown in Figure 3. Vincent and Carey [43] found that if the reflectivity was higher than $40 \mathrm{dBZ}$ above $-10{ }^{\circ} \mathrm{C}$ isotherm, cloud-to-ground lightning would happen within a short time. Wang [44] also provided a similar cloud-to-ground lightning alarm condition. If the $40 \mathrm{dBZ}$ echo top is higher than the $0{ }^{\circ} \mathrm{C}$ isotherm and has the tendency to develop to a higher level, the possibility 
of cloud-to-ground lightning happening is high in this region. If the $40 \mathrm{dBZ}$ echo top is higher than $-10{ }^{\circ} \mathrm{C}$ isotherm, cloud-to-ground lightning will happen in $15 \mathrm{~min}$. If the $40 \mathrm{dBZ}$ echo top is higher than $0{ }^{\circ} \mathrm{C}$ isotherm and lower than $-10^{\circ} \mathrm{C}$ isotherm, and the percentage of the echo volume higher than $40 \mathrm{dBZ}$ divided by that higher than $20 \mathrm{dBZ}$ exceeds 5\%, cloud-to-ground lightning will also happen in $15 \mathrm{~min}$. Based on the alarming conditions above, the forecasted location of cloud-to-ground lightning in Exp. CTL, Exp. radar and Exp. lightn is shown in Figure 5. From 0900 to 1400 UTC, the observed cloud-to-ground lightning was located in the north and center of Anhui Province and moved slowly to the southern part. In Exp. CTL, as the pattern of forecast maximum reflectivity is sporadic, the diagnosed cloud-to-ground lightning is limited, while the location is similar to the observed location. In Exp. radar, the pattern of the diagnosed cloud-to-ground lightning belt is similar to that of the high maximum reflectivity in Figure 3. In the first three hours, the position of diagnosed cloud-to-ground lightning belt is to the north than observation. The area of the diagnosed lightning belt in Shanghai is bigger than the observed lightning belt. In the subsequent two hours, the diagnosed lightning belt reduced quickly, which is lower than that found in Exp. CTL for the same time period. In Exp. lightn, the lightning belt in the north and center of Jiangsu Province is overestimated for the first three hours. However, the diagnosed lightning belt in the center of Anhui Province, Shanghai and north of Zhejiang Province matches the observation well. For the subsequent two hours, Exp. lightn provides the most accurate diagnosed cloud-to-ground lightning belt of all these three experiments. The diagnosed lightning belt is located at the juncture of Anhui, Jiangsu and Zhejiang provinces. In general, based on a comprehensive survey of the performance of these three experiments, Exp. lightn could offer a more accurate diagnosed cloud-to-ground lightning belt.

The NSSL operation platform provides three lightning threat indexes hourly in the lightning forecast. These three lightning threat indexes are the graupel flux on the $-15^{\circ} \mathrm{C}$ isothermal plane, the integration of ice particles in the vertical direction and the weight sum of the formal two indexes (the weights are 0.95 and 0.05 ), respectively [32]. The lightning threat indexes are respectively named LTI01, LTI02 and LTI03. The first lightning threat index, LT I01, is the graupel flux in the mixed-phase region at $-15^{\circ} \mathrm{C}$.

$$
L T I 01=f\left[\left(w q_{g}\right)_{m}\right]
$$

where $w$ is the vertical velocity and $q_{g}$ is the graupel mixing ratio. The subscript $m$ attached to the flux implies evaluation at the $-15{ }^{\circ} \mathrm{C}$ level in the mixed-phase region. The second lightning threat index, LTI02, is based on the gridded vertical integral of graupel, snow and cloud ice.

$$
\text { LTI02 }=h\left[\int \rho\left(q_{g}+q_{i}+q_{s}\right) d z\right]
$$

where $\rho$ is air density, and $q_{g}, q_{i}, q_{s}$ are graupel mixing ratio, cloud ice mixing ratio and snow mixing ratio, respectively. $h$ is a coefficient which is assumed as 0.20 .

$$
L T I 03=0.95 \times L T 01+0.05 \times L T 02
$$

LTI03 is the weight sum of LTI01 and LTI02 gained from formulas (4) and (5). All these three indexes offer the potential forecast of flashes for the subsequent 5 min. Figures 6-8 illustrate these three lightning indexes hourly from 1000 to 1400 UTC. 

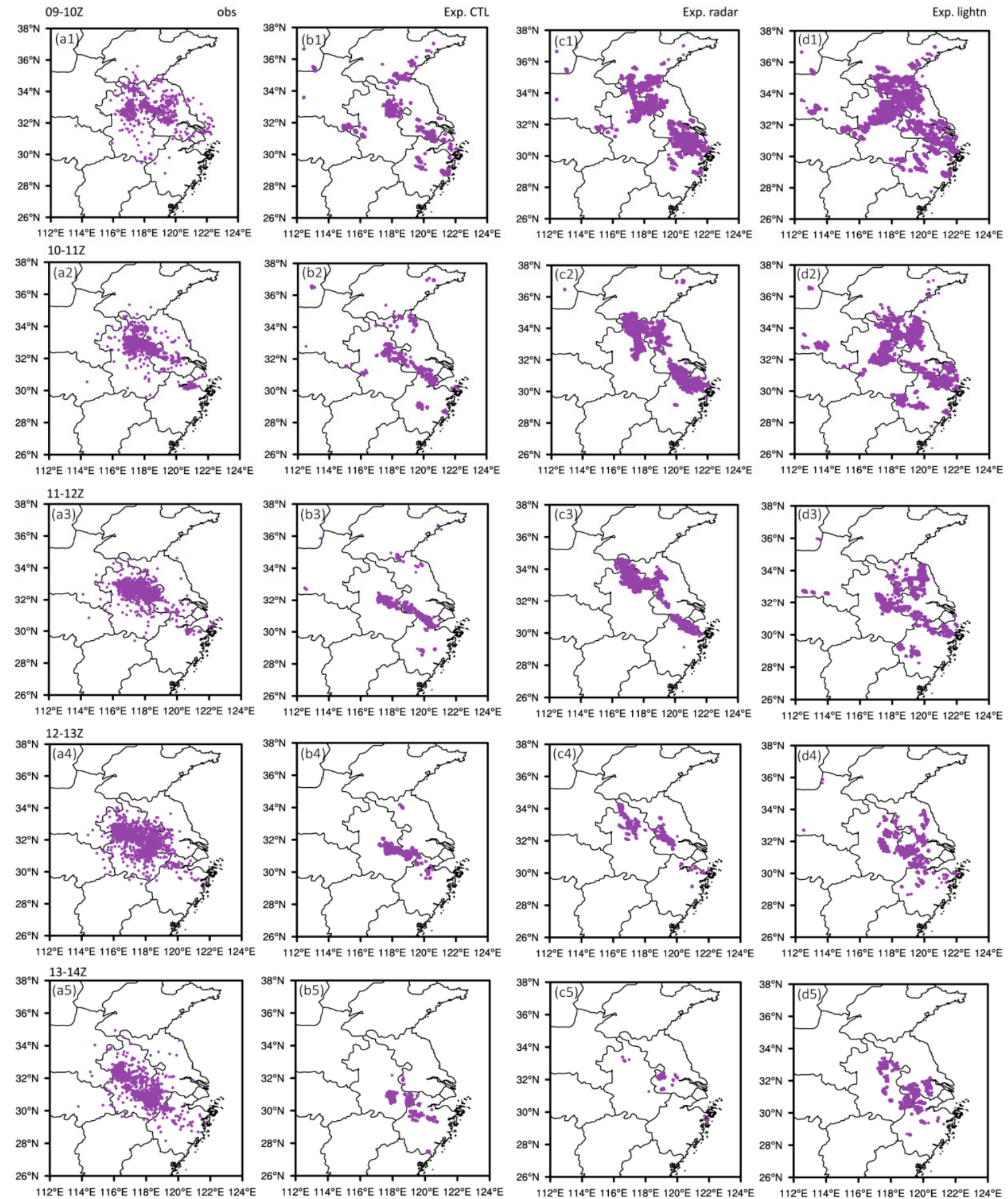

Figure 5. The observed cloud-to-ground lightning location (a) and diagnosed cloud-to-ground lightning location of (b) Exp. CTL, (c) Exp. radar and (d) Exp. lightn from 0900 to 1400 UTC. Row 1 to 6 represents different time point from 1000 to 1500 UTC. 

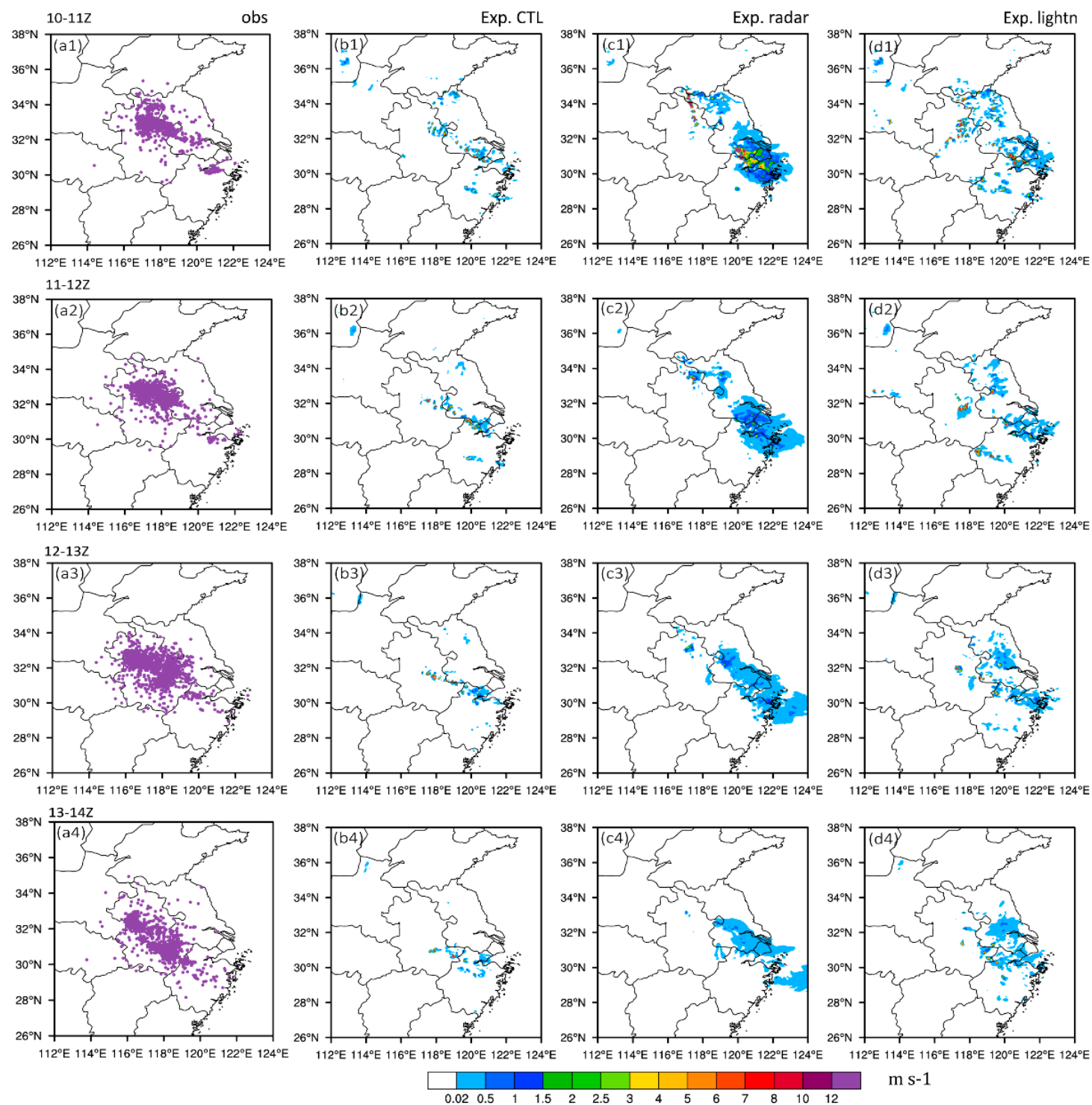

Figure 6. The observed cloud-to-ground lightning location (a) and the diagnosed lightning threat index (the graupel flux on $-15{ }^{\circ} \mathrm{C}$ isothermal plane, LTI01, unit: $\mathrm{m} \cdot \mathrm{s}^{-1}$ ) of (b) Exp. CTL, (c) Exp. radar and (d) Exp. lightn hourly from 1000 to 1400 UTC. Row 1 to 4 represents different time interval from 1000 to 1400 UTC.

For LTI01 in the time interval of 1000-1100 UTC, high values are located in the north and south of Jiangsu Province, the center of Anhui Province, in Shanghai and in the north of Zhejiang Province in all these three experiments. Compared with the observed cloud-to-ground lightning in Figure 4, the first lightning threat index in Exp. CTL is weaker in strength and smaller in area. In Exp. radar, the first lightning index is mainly located in Shanghai and the north of Zhejiang Province, with a maximum value higher than 7 and a larger area than that observed. While in Exp. lightn, the threat is mainly located in the center of Anhui Province, the north of Jiangsu Province, Shanghai and the north of Zhejiang Province, similar to the observed location. The area was not overestimated as in Exp. radar. In the subsequent few hours, LTI01 in Exp. radar was located further east than the observed location and in Exp. CTL and Exp. lightn it was mainly located in the south of Jiangsu Province and center of Anhui Province. LTI01 in Exp. lightn gained more information in Shanghai and the neighboring region, and the area is bigger than that of Exp. CTL. The second lightning threat index is the integration of ice particles in the vertical direction. In Exp. CTL, the distribution of LTI02 is sporadic and the value 
is low, which indicates that there are very few ice particles associated with lightning activity. After assimilating radar reflectivity and lightning data in Exp. radar and Exp. lightn, the content and area of ice particles improved a lot. The adjustment in Exp. radar was stronger than that in Exp. lightn, with a maximum value more than 4 in the time interval from 1000-1100 UTC. The adjustment in Exp. lightn was more reasonable. It effectively complements the lack of Exp. CTL in the central part of Anhui Province. In the subsequent hours, its distribution was similar to the observation in the central part of Anhui Province. LTI03 is the weight sum of the two formal indexes. As the first index occupies a high weight, the distribution of LTI03 is similar to the first index. LTI03 in Exp. CTL is located further east than the observed location, which was mainly focused on Shanghai and the north of Zhejiang Province. LTI03 of Exp. lightn was mainly located in the central and southern parts of Jiangsu Province, the central part of Anhui Province and the northern part of Zhejiang Province, with the value and area smaller than that in the Exp. radar. In the time interval of 1000-1300 UTC, it effectively complements the lack of lightning information for the central part of Anhui Province, the same as for the observed data. Overall, Exp. lightn provides a reasonable lightning threat index distribution among these three experiments, although there exists some spatial displacement to the east.
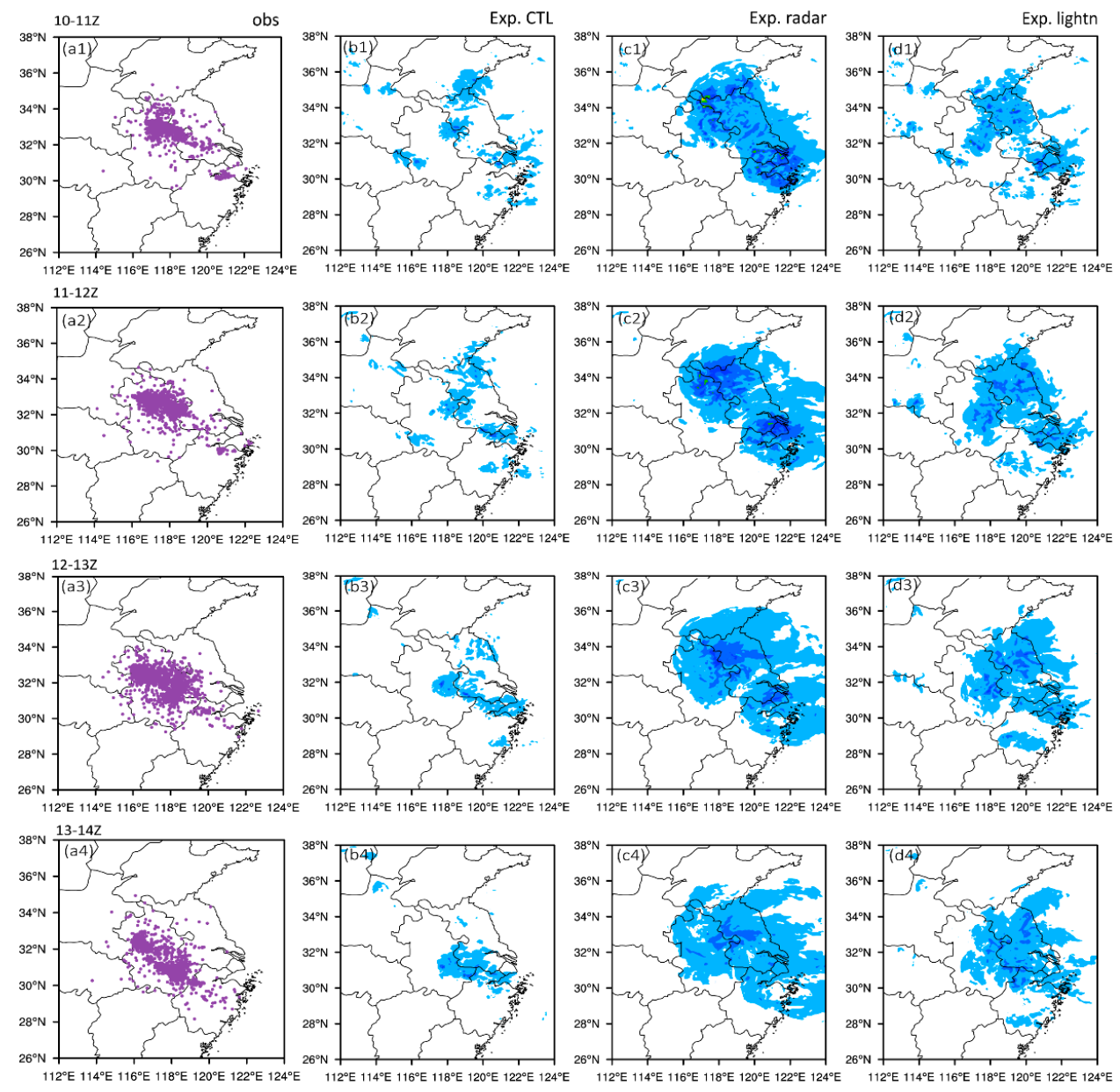

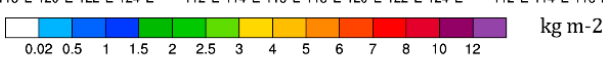

Figure 7. The observed cloud-to-ground lightning location (a) and the diagnosed lightning threat index (the integration of ice particles in the vertical direction, LTI02, unit: $\mathrm{kg} \cdot \mathrm{m}^{-2}$ ) of (b) Exp. CTL, (c) Exp. radar and (d) Exp. lightn hourly from 1000 to 1400 UTC. Row 1 to 4 represents different time interval from 1000 to 1400 UTC. 

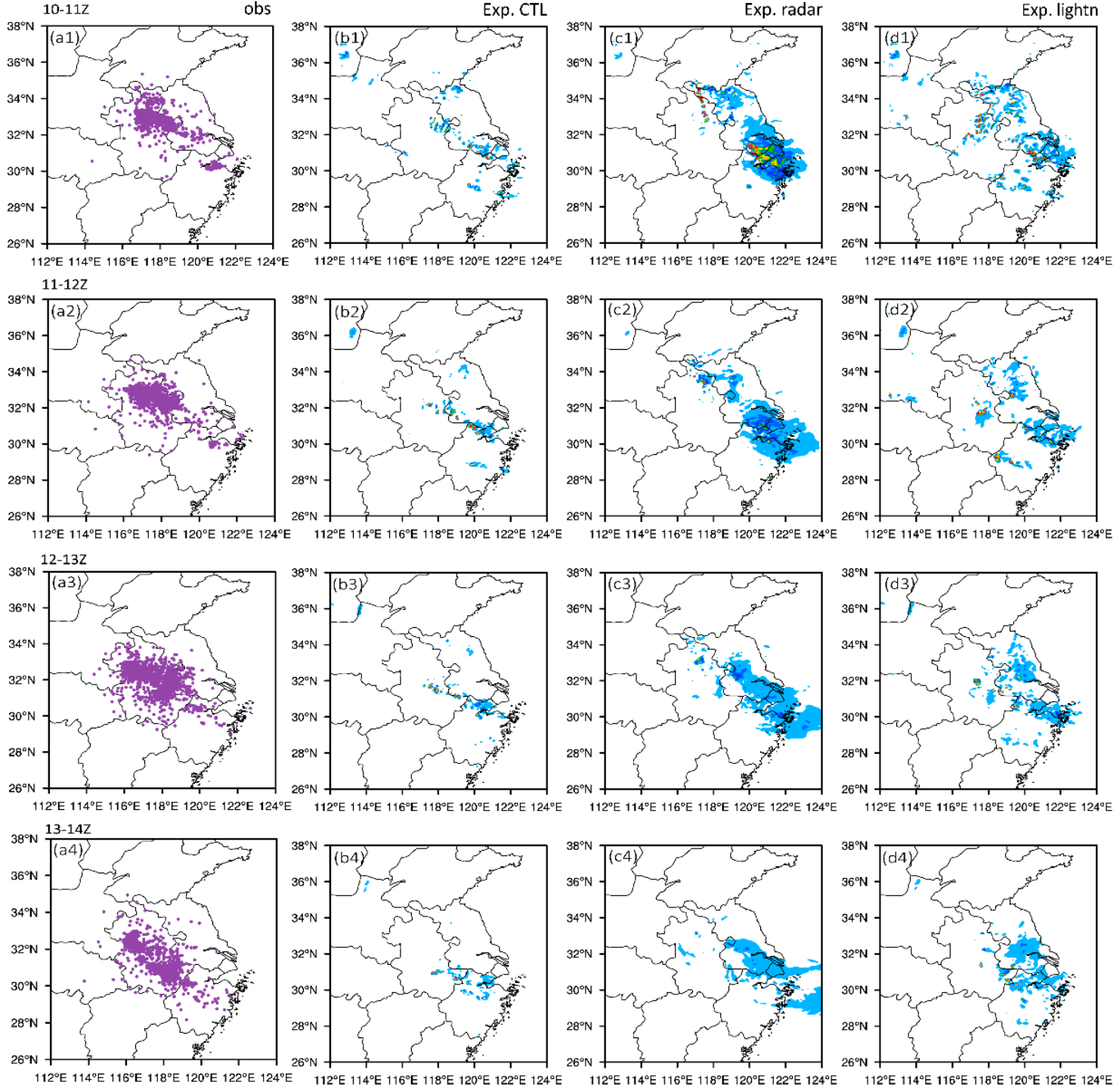

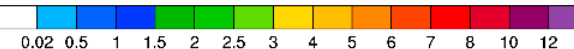

Figure 8. The observed cloud-to-ground lightning location (a) and the diagnosed lightning threat index (the weight sum of the formal two indexes (the weights are 0.95 and 0.05), LTIO3) of (b) Exp. CTL, (c) Exp. radar and (d) Exp. lightn hourly from 1000 to 1400 UTC. Row 1 to 4 represents different time interval from 1000 to 1400 UTC.

\section{Conclusions}

In this study, the main lightning parameterization schemes in the new version of WRF were introduced. The PR92 lightning parameterization scheme that is based on the convective cloud top height was utilized in a convective case study of the event that influenced Jiangsu and Anhui Province on 5 June 2009. At the same time, a diagnosing method basing on temperature and reflectivity and three kinds of lightning threat indexes were used to provide an evaluation of the lightning forecast. Doppler radar reflectivity and lightning location network data were assimilated into WRF via 3DVar to evaluate the subsequent lightning rate forecast. The conclusions are as follows.

(1) Assimilating radar reflectivity and lightning location network data via the 3DVar method can quickly reconstruct the lacking maximum reflectivity according to the observed data. The improvement of the maximum reflectivity forecast maintains well and can last for more than $6 \mathrm{~h}$. 
In the first three hours after assimilation, the overestimation with a maximum value greater than $40 \mathrm{dBZ}$ in Exp. radar was obvious, while that in Exp. lightn was weaker.

(2) In this case study, the PR92 lightning parameterization scheme that is based on the convective cloud top height provided a proper pattern forecast of the accumulated cloud-to-ground lightning rate with a high resolution. However, when the default flash rate factor was utilized, the forecast lightning rate was pretty low, lower than 1 in most regions. Thus, it cannot provide an accurate, available, strong, cloud-to-ground lightning belt forecast.

(3) Based on the reflectivity forecast of these experiments, a short-term cloud-to-ground lightning location diagnosis was made. Compared with the observed data, these two data assimilation experiments can provide a better diagnosed cloud-to-ground lightning belt than the direct lightning forecast basing on the PR92 lightning parameterization scheme.

(4) Additionally, three NSSL lightning threat indexes were also utilized to evaluate the forecast of these three experiments. In Exp. radar, the ice particle adjustment was too strong and the improvement was located further east than the observation. Exp. lightn effectively complements the lack of lightning information in the central part of Anhui Province, as in the observed data.

With this case study, data assimilation experiments can effectively improve reflectivity forecasting and subsequently lightning forecasting. In particular, the lightning data assimilation experiment achieved better improvement. The lightning forecast based on the PR92 lightning parameterization scheme, which is based on the convective cloud top height, could not provide an accurately forecasted strong lightning belt. Maybe the coefficients in the PR92 lightning parameterization scheme or the flash rate factor is not suitable for this case study in China. At the present stage, a proper lightning location forecast can also be gained through the diagnosed method based on reflectivity and temperature, although there exists some spatial displacement in certain regions. As mesoscale models have difficulty predicting the instantaneous placement of thunderstorms, there is a challenge to provide an accurate location of lightning events. With the development of new model versions, physical parameterizations, initialization techniques and forecast ensembles, the precision of forecast models may improve a lot, which could create bright opportunities for lightning forecasts.

Acknowledgments: This research was supported by the National Key Basic Research Program of China (No. 2014CB441406), the National Key Research and Development Program of China (2017YFC1502102), the Startup Foundation for Introducing Talent of Nanjing University of Information Science and Technology and the science technology foundation of China Electric Power Research Institute (1704-00203). The authors thank the Weather Service Forecast Office of Anhui Province for providing radar and lightning data.

Author Contributions: Yi Yang provided the initial idea of this paper. Ying Wang designed, performed the experiment and wrote the paper under the guidance of Yi Yang. Shuanglong Jin provided some useful advice in the analysis and discussion section.

Conflicts of Interest: The authors declare no conflict of interest.

\section{References}

1. Schonland, B.F.J.; Malan, D.J.; Collens, H. Progressive Lightning-II. Proc. R. Soc. A 1938, 168, 455-469. [CrossRef]

2. Thomson, E.M.; Uman, M.A.; Beasley, W.H. Speed and Current for Lightning Stepped Leaders Near Ground as Determined from Electric Field Records. J. Geophys. Res. 1985, 90, 8136-8142. [CrossRef]

3. Reynolds, S.E.; Brook, M.; Gourley, M.F. Thunderstorm Charge Separation. J. Meteorol. 1957, 14, 426-436. [CrossRef]

4. Latham, J.; Mason, B.J. Generation of electric charge associated with the formation of soft hail in thunderclouds. Proc. R. Soc. A 1961, 260, 537-549.

5. Baker, B.; Baker, M.B. The influence of diffusional growth rates on the charge transfer accompanying rebounding collisions between ice crystals and soft hailstones. Q.J.R. Meteorol. Soc. 1987, 113, 1193-1215. [CrossRef] 
6. Saunders, C.P.R.; Keith, W.D.; Mitzeva, R.P. The effect of liquid water on thunderstrom charging. J. Geophys. Res. 1991, 96, 11007-11017. [CrossRef]

7. Michaelides, S.; Savvidou, K.; Nicolaides, K. Relationships between lightning and rainfall intensities during rainy events in Cyprus. Adv. Geosci. 2010, 23, 87-92. [CrossRef]

8. Stolz, D.C.; Businger, S.; Terpstra, A. Refining the relationship between lightning and convective rainfall over the ocean. J. Geophys. Res. Atmos. 2014, 119, 964-981. [CrossRef]

9. Tapia, A.; Smith, J.A.; Dixon, M. Estimation of convective rainfall from lightning observations. J. Appl. Meteorol. 1998, 37, 1497-1509. [CrossRef]

10. Zhou, Y.; Qie, X.; Soula, S. A study of the relationship between cloud-to-ground lightning and precipitation in the convective weather system in China. Ann. Geophys. 2002, 20, 107-113. [CrossRef]

11. Stefănescu, R.; Navom, M.; Fuelberg, H.; Marchand, M. 1D+4D-Var data assimilation of lightning with WRFDA system using nonlinear observation operators. arXiv preprint, 2013.

12. Tinmaker, M.I.R.; Aslam, M.Y.; Chate, D.M. Lightning activity and its association with rainfall and convective available potential energy over Maharashtra, India. Nat. Hazards 2015. [CrossRef]

13. Price, C.; Rind, D. A simple lightning parameterization for calculating global lightning distributions. J. Geophys. Res. 1992, 97, 9919-9933. [CrossRef]

14. Benjamin, S. Assimilation of lightning data into RUC model convection forecasting. Presented at the Second Conference on Meteorological Applications of Lightning Data, Tucson, AZ, USA, 31 January 2006; Available online: https:/ / ams.confex.com/ams / Annual2006/techprogram/paper_105079.htm (accessed on 9 March 2018).

15. Benjamin, S.; Weygandt, S.; Brown, J.; Smirnova, T.; Devenyi, D.; Brundage, K.; Grell, G.; Peckham, S.; Schlatter, T.; Smith, T. From the Radar-Enhanced RUC to the WRF-Based Rapid Refresh. Presented at the 18th Conference on Numerical Weather Prediction, Park City, UT, USA, 25 June 2007; American Meteorology Society. Available online: https:/ / ams.confex.com/ams/22WAF18NWP/techprogram/paper_124827.htm (accessed on 9 March 2018).

16. Benjamin, S.G.; Dévényi, D.; Weygandt, S.S.; Brundage, K.J.; Brown, J.M.; Grell, G.A.; Kim, D.; Schwartz, B.E.; Smirnova, T.G.; Smith, T.L. An hourly assimilation-forecast cycle: The RUC. Mon. Weather. Rev. 2004, 132, 495-518. [CrossRef]

17. Weygandt, S.S.; Benjamin, S.G.; Smirnova, T.G.; Brown, J.M. Assimilation of lightning data using a diabatic digital filter within the Rapid Update Cycle. In Proceedings of the 20th International Lightning Detection Conference, Tucson, AZ, USA, 21-23 April 2008; Available online: https: / / my.vaisala.net/en/events/ildcilmc/Documents / Assimilation\%20of\%20Lightning\%20Data\% 20Using\%20a\%20Diabatic\%20Digital\%20Filter\%20Within\%20the\%20Rapid\%20Update\%20Cycle.PDF (accessed on 9 March 2018).

18. Bovalo, C.; Barthe, C.; Pinty, J.-P.; Chong, M. Potential of cloud-resolving model parameters to be used as proxies for the total flash rate. In Proceedings of the XV International Conference on Atmospheric Electricity, Norman, OK, USA, 15-20 June 2014.

19. Barthe, C.; Deierling, W.; Barth, M.C. Estimation of total lightning from various storm parameters: A cloud-resolving model study. J. Geophys. Res. 2010, 115. [CrossRef]

20. Deierling, W.; Petersen, W.A.; Latham, J.; Ellis, S.; Christian, H.J. The relationship between lightning activity and ice fluxes in thunderstorms. J. Geophys. Res. 2008, 113. [CrossRef]

21. Deierling, W.; Petersen, W.A. Total lightning activity as an indicator of updraft characteristics. J. Geophys. Res. 2008, 113. [CrossRef]

22. Kuhlman, K.M.; Ziegler, C.L.; Mansell, E.R.; MacGorman, D.R.; Straka, J.M. Numerically simulated electrification and lightning of the 29 June 2000 STEPS supercell storm. Mon. Weather. Rev. 2006, 134, 2734-2757. [CrossRef]

23. Alexander, G.D.; Weinman, J.A.; Karyampudi, V.M.; Olson, W.S.; Lee, A.C.L. The Effect of Assimilating Rain Rates Derived from Satellites and Lightning on Forecasts of the 1993 Superstorm. Mon. Weather. Rev. 1999, 127, 1433-1457. [CrossRef]

24. Chang, D.-E.; Weinman, J.A.; Morales, C.A.; Olson, W.S. The Effect of Spaceborne Microwave and Ground-Based Continuous Lightning Measurements on Forecasts of the 1998 Groundhog Day Storm. Mon. Weather. Rev. 2001, 129, 1809-1833. [CrossRef] 
25. Mansell, E.R.; Ziegler, C.L.; MacGorman, D.R. A Lightning Data Assimilation Technique for Mesoscale Forecast Models. Mon. Weather Rev. 2007, 135, 1732-1748. [CrossRef]

26. Fierro, A.O.; Mansell, E.R.; Ziegler, C.L.; MacGorman, D.R. Application of a Lightning Data Assimilation Technique in the WRF-ARW Model at Cloud-Resolving Scales for the Tornado Outbreak of 24 May 2011. Mon. Weather. Rev. 2012, 140, 2609-2627. [CrossRef]

27. Qie, X.; Zhu, R.; Yuan, T.; Wu, X.; Li, W.; Liu, D. Application of total-lightning data assimilation in a mesoscale convective system based on the WRF model. Atmos. Res. 2014, 145-146, 255-266. [CrossRef]

28. Wang, Y.; Yang, Y.; Wang, C. Improving forecasting of strong convection by assimilating cloud-to-ground lightning data using the physical initialization method. Atmos. Res. 2014, 150, 31-41. [CrossRef]

29. Yang, Y.; Wang, Y.; Zhu, K. Assimilation of Chinese Doppler Radar and Lightning Data Using WRF-GSI: A Case Study of Mesoscale Convective System. Adv. Meteorol. 2015. [CrossRef]

30. Wang, Y.; Yang, Y.; Qiu, X. Assimilating Cloud-to-ground Lightning Data Using Ensemble Square Root Filter. J. Arid Meteorol. 2015, 33, 761-768. (In Chinese)

31. Wang, Y.; Yang, Y.; Liu, D.; Zhang, D.; Yao, W.; Wang, C. A Case Study of Assimilating Lightning-proxy Relative Humidity with WRF-3DVAR. Atmosphere 2017, 8, 55. [CrossRef]

32. McCaul, E.W., Jr.; Goodman, S.J.; LaCasse, K.M.; Cecil, D.J. Forecasting Lightning Threat Using Cloud-Resolving Model Simulations. Weather Forecast. 2009, 24, 709-729. [CrossRef]

33. Wong, J.; Barth, M.C.; Noone, D. Evaluating a lightning parameterization based on cloud-top height for mesoscale numerical model simulations. Geosci. Model Dev. 2013, 6, 429-443. [CrossRef]

34. Williams, E.R.; Weber, M.E.; Orville, R.E. The relationship between lightning type and convective state of thunderclouds. J. Geophys. Res. 1989, 94, 13213-13220. [CrossRef]

35. Jorgensen, P.D.; Lemone, M.A. Vertical velocity characteristics of oceanic convection. J. Atmos. Sci. 1989, 46, 621-640. [CrossRef]

36. Xiao, Q.; Guo, Y.H.; Sun, J.; Lee, W.C.; Barker, D.M.; Lim, E. An Approach of Radar Reflectivity Data Assimilation and Its Assessment with the Inland QPF of Typhoon Rusa (2002) at Landfall. J. Appl. Meteorol. Clim. 2007, 46, 14-22. [CrossRef]

37. Sun, J.; Crook, N.A. Dynamical and Microphysical Retrieval from Doppler Radar Observations Using a Cloud Model and Its Adjoint. Part I: Model Development and Simulated Data Experiments. J. Atmos. Sci. 1997, 54, 1642-1661. [CrossRef]

38. Lin, Y.-L.; Farley, R.D.; Orville, H.D. Bulk parameterization of the snow field in a cloud model. J. Appl. Meteorol. 1983, 22, 1065-1092. [CrossRef]

39. Mlawer, E.J.; Taubman, S.J.; Brown, P.D.; Iacono, M.J.; Clough, A.S. Radiative transfer for inhomogeneous atmospheres: RRTM, a validated correlated-k model for the longwave. J. Geophys. Res. Atmos. 1997, 102, 16663-16682. [CrossRef]

40. Chou, M.-D.; Suarez, M.J. A solar radiation parameterization for atmospheric studies. NASA Tech. Rep. Serv. 1999, 15, 104606.

41. Janjić, Z.I. Nonsingular implementation of the Mellor-Yamada level 2.5 scheme in the NCEP Meso model. NCEP Office Note 2002, 437, 61.

42. Mellor, G.L.; Yamada, T. Development of a turbulence closure model for geophysical fluid problems. Rev. Geophys. 1982, 20, 851-875. [CrossRef]

43. Vincent, B.R.; Carey, L.D. Using WSR-88D Reflectivity for the Prediction of Cloud-to-ground Lightning: A Central North Carolina Study. National Weather Dig. 2004, 27, 35-44.

44. Wang, F. The Research on the Application of Radar Data to Lightning Alarming in Beijing Area. Master's Thesis, Chinese Academy of Meteorological Sciences, Beijing, China, 2007.

(C) 2018 by the authors. Licensee MDPI, Basel, Switzerland. This article is an open access article distributed under the terms and conditions of the Creative Commons Attribution (CC BY) license (http:/ / creativecommons.org/licenses/by/4.0/). 